\title{
Prevalence and associated factors of diabetes mellitus among tuberculosis patients in Hanoi, Vietnam
}

\author{
N. B. Hoa ${ }^{1,2^{*}}$ (D, P. D. Phuc ${ }^{3,4}$, N. T. Hien ${ }^{3,4}$, V. Q. Hoa ${ }^{1}$, P. H. Thuong ${ }^{5}$, P. T. Anh 5 and N. V. Nhung ${ }^{1,6}$
}

\begin{abstract}
Background: Diabetes mellitus (DM) is recognized as an important comorbidity for the development of tuberculosis (TB). With the increase of DM burden globally, concerns have been raised about the emerging co-epidemics of DM and TB, especially in low- and middle-income countries.

Methods: A facility-based, cross-sectional study was carried out in all 30 district TB units in Hanoi, Vietnam. All eligible, diagnosed TB patients aged 15 years old or older were asked to provide consent and were screened for diabetes using fasting blood glucose (FBG). Pre-tested semi-structured questionnaires were used for collecting demographic data, lifestyle habits and clinical data. Identification of pre-diabetes or diabetes in TB patients was done in accordance to parameters set by the American Diabetes Association (2016).

Results: Of 870 eligible TB patients, 831 (95.5\%) participated in the study. Of those, 241 (29\%; 95\%Cl: 25.9-32.1\%) were prediabetic and $114(13.7 \%$; 95\%Cl: 11.4-16.1\%) were found to have DM. The risk of DM was higher in patients belonging to the age group 40-64 years (OR 6.09; $95 \% \mathrm{Cl} 2.81-13.2)$; or the age group 65 years or older (OR 2.65; 95\%Cl 1.65-4.25) or who have a family history of DM (OR 2.71; 95\%Cl 1.33-5.50).

Conclusions: This study demonstrated high prevalence of DM and prediabetes among TB patients in Hanoi, Vietnam. National Tuberculosis Programme needs to establish a systematic screening process for DM among TB patients.
\end{abstract}

Keywords: Tuberculosis (TB), diabetes mellitus (DM), prevalence, Risk factors, Vietnam

\section{Background}

Vietnam is a lower middle-income country and ranks 15th amongst the 30 highest Tuberculosis (TB) incidences globally [1]. The World Health Organization (WHO) estimated that there were 126,000 TB incidence cases in Viet Nam in 2016, which accounts for 123 cases per 100,000 population. The number of reported TB cases in Vietnam in 2016 was 106,527 TB cases [1]. The burden of Diabetes mellitus (DM) is increasing worldwide with the International Diabetes Federation (IDF) estimating that approxiately 425 million people are living with diabetes, amounting to $8.8 \%$ of the global

\footnotetext{
* Correspondence: nguyenbinhhoatb@yahoo.com

'Vietnam National Lung Hospital, National Tuberculosis Programme Vietnam, 463 Hoang Hoa Tham street, Badinh District, Hanoi, Vietnam

${ }^{2}$ Centre for Operational Research, International Union Against Tuberculosis and Lung Disease, Paris, France

Full list of author information is available at the end of the article
}

population [2]. It was also estimated that approximately half of this population was unaware of their DM status in 2016 [2]. Low- and middle-income countries account for approximately $80 \%$ of the global DM burden, and more than $90 \%$ of the global TB burden [2].

$\mathrm{DM}$ is recognized as an important comorbidity for the development of $\mathrm{TB}$, with those who have $\mathrm{DM}$ having a two to three times higher risk of developing TB than those without DM [3-5]. This leads to a higher prevalence rate of TB among DM patients; the rate of DM is also higher among TB patients than in general population [3]. People with TB and DM generally have a poorer response to $\mathrm{TB}$ treatments and increased the risk of relapse and death $[3,6,7]$. With the increase of DM burden globally, concerns have been raised about the emerging co-epidemics of $\mathrm{DM}$ and $\mathrm{TB}$, especially in low- and middle-income countries. 
In 2011, the WHO and the International Union Against Tuberculosis and Lung Disease (the UNION) recommended that $\mathrm{TB}$ patients should be routinely screened for DM [3]. The framework recommended all countries should be surveilling diabetes among TB patients [3]. Many studies conducted in different countries have shown the prevalence of DM among TB patients to be approximately $12-44 \%$ [8]. Currently, in Vietnam, there is no systematic screening for DM amongst TB patients and limited studies investigating the prevalence of DM amongst TB patients. One study conducted in the National Lung Hospital in 2006-2008 found the prevalence of DM among TB patients to be $8.8 \%$ [9].

Hanoi is the capital of Vietnam, has a high proportion of the total TB cases reported in the country. In 2016, Hanoi detected and reported 4382 TB cases, amounting to 59 cases per 100,000 population. This study aimed to identify the prevalence and some associated risk factors of DM amongst TB patients attending district TB units in Hanoi, Vietnam. The results will look to help to establish linkages between TB and DM and provide data to estimate the needs and requirements for DM care services among $\mathrm{TB}$ patients in Vietnam.

\section{Methods}

\section{Setting and study population}

This facility-based, cross-sectional study was conducted in all 30 districts of Hanoi where the total population was estimated at 7,328,400 in 2016. The study population included all TB patients aged over 15 years old, who had been diagnosed and enrolled for TB treatment from October to December of 2016.

The sample size was calculated based on the standard formula for estimating a single population:

$$
n=\frac{Z_{1-\alpha / 2}^{2} \cdot p \cdot(1-p)}{d^{2}} \times D E .
$$

A previous study conducted in 2006-2008, at the National Lung Hospital in Hanoi, investigated the DM prevalence among 2867 newly diagnosed TB patients and discovered the DM prevalence to be $8.8 \%$ [9]. A similar DM prevalence was assumed for this study, with a 95\% confidence interval and $20 \%$ relative precision. With a cluster sampling of 1.5 the sample size was calculated to be 740 participants. To account for an estimated non-participation rate of $15 \%$, the final sample size required for this study was considered as $870 \mathrm{~TB}$ patients.

\section{Sampling method}

Patients who were aged 15 years or above and had been diagnosed with TB in any 30 districts of Hanoi were considered for the study. Participants were enrolled for
TB treatment between October and December of 2016. Recruitment was continuous until the required sample size was met.

\section{Data collection}

All consenting participants were interviewed using pre-tested questionnaires to collect the patient's information. Questionnaires collected socio-demographic variables including age, sex, weight, height, education, occupation, marital status, average monthly income and HIV status. The questionnaires also collected information around lifestyle factors including smoking, drinking and exercise. The participant's disease profile and clinical records pertaining to TB and DM status were also collected. TB patients were asked about their DM status. If the TB patients were diagnosed with DM prior to the study, they were not further investigated for the DM, and the patients were requested to provide their most recent $\mathrm{DM}$ test results. If the $\mathrm{TB}$ patients were did not know or were unsure about their DM status, they were requested to undergo a fasting blood glucose (FBG) test, after the cessation of eating for at least $8 \mathrm{~h}$.

\section{Definition}

TB patients' diagnosis and treatment outcomes were categorized following NTP's guidelines, which are in line with WHO's recommendations [10].

Patients with FBG levels $\geq 126 \mathrm{mg} / \mathrm{dl}(\sim 7 \mathrm{mmol} / \mathrm{l})$ were diagnosed as having DM. Patients with FBG levels between 100 and $126 \mathrm{mg} / \mathrm{dl}(5.6-6.9 \mathrm{mmol} / \mathrm{l})$ were diagnosed as having impaired fasting glucose (IFG), or prediabetes, in line with guidance from the American Diabetes Association (ADA) [11].

Classification of socioeconomic status was determined following Vietnam Government criteria, issued by Prime Minister for the period 2016-2020 [12]. A "poor" household is one whose per capita income does not exceed 700,000 Vietnam Dong (VND) in rural area and 900,000 VND in urban area. Households are also classified as poor if their per capita income is between 700,000 - 1,000,000 VND in rural areas or 900,000-1,300,000 VND in urban areas when households have unfavourable outcomes in at least three of ten basic social service indicators (access to medical services, health insurance, education level of adults, school attendance of children, housing quality, average housing area per capital, residential water sources, hygienic latrines and toilets, telecom services, and assets to serve information access (TV, computer, radio, other). A "near-poor" household is one whose per capita income is between 700,000-1,000,000 VND or $900,000-1,300,000$ VND in rural or urban areas, respectively, and have unfavourable outcomes in at least three of ten basic social service indicators A "medium" household is a household whose per capital income is between 1,000,000-1,500,000 
VND in rural area and between 1,300,000-1,950,000 VND in urban area [12].

\section{Statistical analysis}

Data was entered into EpiData version 3.1 (EpiData Association, Odense, Denmark) and the analysis were carried out using Stata v.13 software (Stata Corporation, College Station, TX, USA). The main outcomes of the analysis were the number and proportion of TB patients with DM and prediabetes; data was then stratified by sex, age, education, occupation, marital status, residence, monthly incomes, socio-economic status and body mass index (BMI). The proportion of TB patients with DM and prediabetes was also stratified by lifestyle and other factors such as physical activity, smoking, drinking status, family history of DM, type of TB, treatment category and HIV status. Single proportion with $95 \%$ confidence interval (CI) was calculated. A Kruskal-Wallis test and Cuzick test were used for the nonparametric data and to test for trend across ordered groups. Odds ratio (OR) with 95\% CI were used to describe association between groups. Multivariate logistic regression analysis was performed to calculate adjusted OR for analyzing the association of the related risk factors with the outcome variables.

\section{Ethics approval}

The study protocol was approved by the Institutional Review Board of the National Lung Hospital, Hanoi, Vietnam. Patients diagnosed with DM received appropriate treatment. Written informed consent was obtained from each participant prior to enrolment.

\section{Results}

A total of 851 eligible TB patients aged $\geq 15$ years old were enrolled during the study period. 831 (97.7\%) patients consented and were interviewed.

\section{General characteristics}

The socio-demographic characteristics of study's participants are presented in Table 1. Of 831 TB patients, $549(66.1 \%)$ were males and $282(33.9 \%)$ were females. The mean age of participants was 48.4 (standard deviation (SD): 18.2). More than half of the participants (531, 63.9\%) had a secondary or high school education. The number of participants residing in urban areas was $401(48.3 \%)$ and $468(56.3 \%)$ had a monthly income less than 3,000,000 VND. The mean of BMI was $19.6 \mathrm{~kg} / \mathrm{m}^{2}$, (SD 3.0) with $34.8 \%$ patients was classified as underweight.

\section{Prevalence of prediabetes and DM among TB patients}

The overall prevalence of prediabetes and DM among TB patients and stratified by general characteristics are shown
Table 1 General characteristics of Tuberculosis patients enrolled for the study, Hanoi, Vietnam, 2016. $(n=831)$

\begin{tabular}{|c|c|c|}
\hline General characteristic & $n$ & $\%$ \\
\hline $\begin{array}{l}\text { Total } \\
\end{array}$ & 831 & 100.0 \\
\hline \multicolumn{3}{|l|}{ Sex } \\
\hline Male & 549 & 66.1 \\
\hline Female & 282 & 33.9 \\
\hline \multicolumn{3}{|l|}{ Age in years } \\
\hline $15-24$ & 92 & 11.1 \\
\hline $25-34$ & 133 & 16.0 \\
\hline $35-44$ & 142 & 17.1 \\
\hline $45-54$ & 137 & 16.5 \\
\hline $55-64$ & 175 & 21.1 \\
\hline 65 years and older & 152 & 18.3 \\
\hline Mean age (SD) & $48.4(18.2)$ & \\
\hline \multicolumn{3}{|l|}{ Education } \\
\hline Primary and lower & 143 & 17.2 \\
\hline Secondary; high school & 531 & 63.9 \\
\hline Colleagues/University or higher & 157 & 18.9 \\
\hline \multicolumn{3}{|l|}{ Occupation } \\
\hline Unemployed & 113 & 13.6 \\
\hline Farmer & 259 & 31.2 \\
\hline Self-employed & 49 & 5.9 \\
\hline Government employed/Student; pupil / retired & 410 & 49.3 \\
\hline \multicolumn{3}{|l|}{ Marital status } \\
\hline Single & 158 & 19.0 \\
\hline Married & 629 & 75.7 \\
\hline Divorced / separated & 44 & 5.3 \\
\hline \multicolumn{3}{|l|}{ Residence } \\
\hline Rural & 430 & 51.7 \\
\hline Urban & 401 & 48.3 \\
\hline \multicolumn{3}{|l|}{ Monthly Income (VND) } \\
\hline$<3,000,000$ ( 132.3 US\$) & 468 & 56.3 \\
\hline $3,000,000-5,000,000(\sim 132.3-220.5$ US\$) & 220 & 26.5 \\
\hline$>5,000,000$ ( 220.5 US\$) & 143 & 17.2 \\
\hline \multicolumn{3}{|l|}{ Socio-economic status } \\
\hline Poor/ near-poor household & 103 & 12.4 \\
\hline Medium household and above & 728 & 87.6 \\
\hline \multicolumn{3}{|l|}{$\mathrm{BMl}, \mathrm{kg} / \mathrm{m} 2$} \\
\hline Underweight, $<18.5$ & 289 & 34.8 \\
\hline Normal, 18.5-24.9 & 518 & 62.3 \\
\hline Overweight, $>=25$ & 24 & 2.9 \\
\hline Mean (SD) & 19.6 (3.0) & \\
\hline
\end{tabular}

*SD Standard deviation; VND Vietnam dong; BMI Body mass index 
Table 2 The prevalence of pre-diabetes and DM among TB patients, in Hanoi, Vietnam, 2016 ( $n=831)$

\begin{tabular}{|c|c|c|c|c|c|c|c|}
\hline & $\begin{array}{l}\text { Total TB patients } \\
\text { evaluated for DM (n) }\end{array}$ & $\begin{array}{l}\text { TB patients with } \\
\text { pre-DM (n) }\end{array}$ & $\begin{array}{l}\text { Prevalence of } \\
\text { pre-DM } \\
(\% ; 95 \% \mathrm{Cl})\end{array}$ & $p$ value ${ }^{*}$ & $\begin{array}{l}\text { TB patients } \\
\text { with DM (n) }\end{array}$ & $\begin{array}{l}\text { Prevalence of DM } \\
(\% ; 95 \% \mathrm{Cl})\end{array}$ & $p$ value* \\
\hline Total & 831 & 241 & $29.0(25.9-32.1)$ & & 114 & $13.7(11.4-16.1)$ & \\
\hline Sex & & & & 0.274 & & & 0.007 \\
\hline Male & 549 & 166 & $30.2(26.4-34.1)$ & & 88 & $16.0(13.0-19.1)$ & \\
\hline Female & 282 & 75 & $26.6(21.4-31.8)$ & & 26 & $9.2(5.8-12.6)$ & \\
\hline Age, years & & & & $<0.001$ & & & $<0.001$ \\
\hline $15-24$ & 92 & 19 & $20.7(12.2-29.1)$ & & 5 & $5.4(0.7-10.1)$ & \\
\hline $25-34$ & 133 & 23 & $17.3(10.8-23.8)$ & & 6 & $4.5(0.9-8.1)$ & \\
\hline $35-44$ & 142 & 37 & $26.1(18.7-33.4)$ & & 16 & $11.3(6.0-16.5)$ & \\
\hline $45-54$ & 137 & 47 & $34.3(26.3-42.4)$ & & 27 & $19.7(13.0-26.5)$ & \\
\hline $55-64$ & 175 & 61 & $34.9(27.7-42.0)$ & & 33 & $18.9(13.0-24.7)$ & \\
\hline$\geq 65$ & 152 & 54 & $35.5(27.8-43.2)$ & & 27 & $17.8(11.6-23.9)$ & \\
\hline Education & & & & 0.002 & & & 0.624 \\
\hline Primary or lower & 143 & 49 & $34.3(26.4-42.1)$ & & 19 & $13.3(7.7-18.9)$ & \\
\hline Secondary; high school & 531 & 163 & $30.7(26.8-34.6)$ & & 77 & $14.5(11.5-17.5)$ & \\
\hline Colleagues/University or higher & 157 & 29 & $18.5(12.3-24.6)$ & & 18 & $11.5(6.4-16.5)$ & \\
\hline Occupation & & & & 0.002 & & & 0.328 \\
\hline Unemployed & 113 & 35 & $31.0(22.3-39.6)$ & & 15 & $13.3(6.9-19.6)$ & \\
\hline Farmer & 259 & 96 & $37.1(31.1-43.0)$ & & 28 & $10.8(7.0-14.6)$ & \\
\hline Self-employed & 49 & 15 & $30.6(17.2-44.0)$ & & 9 & $18.4(7.1-29.6)$ & \\
\hline $\begin{array}{l}\text { Government employed/Student; } \\
\text { pupil / retired }\end{array}$ & 410 & 95 & $23.2(19.1-27.3)$ & & 62 & $15.1(11.6-18.6)$ & \\
\hline Marital status & & & & 0.062 & & & 0.481 \\
\hline Single & 158 & 34 & $21.5(15.0-28.0)$ & & 17 & $10.8(5.9-15.6)$ & \\
\hline Married & 629 & 192 & $30.5(26.9-34.1)$ & & 91 & $14.5(11.7-17.2)$ & \\
\hline Divorced/separated & 44 & 15 & $34.1(19.5-48.7)$ & & 6 & $13.6(3.1-24.2)$ & \\
\hline Residence & & & & 0.084 & & & 0.107 \\
\hline Rural & 430 & 136 & $31.6(27.2-36.0)$ & & 51 & $11.9(8.8-14.9)$ & \\
\hline Urban & 401 & 105 & $26.2(21.9-30.5)$ & & 63 & $15.7(12.1-19.3)$ & \\
\hline Monthly income (VND) & & & & $<0.001$ & & & 0.636 \\
\hline$<3,000,000(\sim 132.3$ US\$) & 468 & 153 & $32.7(28.4-37.0)$ & & 60 & $12.8(9.8-15.9)$ & \\
\hline $\begin{array}{l}3,000,000-5,000,000 \\
(\sim 132.3-220.5 \text { US\$) }\end{array}$ & 220 & 65 & $29.5(23.5-35.6)$ & & 35 & $15.9(11.0-20.8)$ & \\
\hline$>5,000,000(\sim 220.5$ US\$) & 143 & 23 & $16.1(10.0-22.2)$ & & 19 & $13.3(7.7-18.9)$ & \\
\hline Socio-economic status & & & & 0.794 & & & 0.790 \\
\hline Poor/ near-poor household & 103 & 31 & $30.1(21.1-39.1)$ & & 15 & $14.6(7.6-21.5)$ & \\
\hline Medium household and above & 728 & 210 & $28.8(25.5-32.1)$ & & 99 & $13.6(11.1-16.1)$ & \\
\hline $\mathrm{BMl}, \mathrm{kg} / \mathrm{m} 2$ & & & & 0.077 & & & 0.304 \\
\hline Underweight, $<18.5$ & 289 & 94 & $32.5(27.1-38.0)$ & & 38 & $13.1(9.2-17.1)$ & \\
\hline Normal, 18.5-24.9 & 518 & 142 & $27.4(23.6-31.3)$ & & 69 & $13.3(10.4-16.3)$ & \\
\hline Overweight, $>=25$ & 24 & 5 & $20.8(3.3-38.4)$ & & 7 & $29.2(9.6-48.8)$ & \\
\hline
\end{tabular}

TB Tuberculosis; DM Diabetes mellitus; CI Confidence interval; SD Standard deviation; VND Vietnam dong; BMI Body mass index ${ }^{*} p$ value by Kruskal-Wallis test and Cuzick test were used for the nonparametric data and to test for trend across ordered groups 
in Table 2. Of $831 \mathrm{~TB}$ patients, 241 (29\%; 95\% CI: 25.9-32.1\%) were prediabetic and 114 (13.7\%; 95\% CI: 11.4-16.1\%)) were found to have DM. The prevalence of DM was higher among males than females $(16.0 \%$ vs $9.2 \%)$ and was shown to increase with age. The incidence of prediabetes was also higher among those in older age groups, those who had primary or lower education levels, those who worked as farmers and in those with a monthly income less than 3,000,000 VND.

\section{Lifestyle factors}

The proportion of DM among TB patients with a family history of DM was 29\% (95\% CI: $18.0-40.0 \%$ ) higher than those who did not (12.4, 95\% CI: 10.0 $14.7 \%)$.

The level of pre-diabetes in TB patients who were currently smoking was $34.3 \%$ (95\% CI: $25.2-43.4 \%)$ higher than those never smoked (26.3\%; 95\% CI: 22.4-33.1\%). The proportion of prediabetes was also higher among TB patients with a family history of DM, with the

Table 3 The prevalence of pre-diabetes and DM among TB patients, stratified by lifestyles and risk factors, in Hanoi, Vietnam, 2016

\begin{tabular}{|c|c|c|c|c|c|c|c|}
\hline & $\begin{array}{l}\text { Total TB patients } \\
\text { evaluated for DM (n) }\end{array}$ & $\begin{array}{l}\text { TB patients with } \\
\text { pre-DM (n) }\end{array}$ & $\begin{array}{l}\text { Prevalence of pre-DM (\%; } \\
95 \% \mathrm{Cl})\end{array}$ & $p$ value & $\begin{array}{l}\text { TB patients with } \\
\text { DM (n) }\end{array}$ & $\begin{array}{l}\text { Prevalence of DM } \\
(\% ; 95 \% \mathrm{Cl})\end{array}$ & $p$ value \\
\hline Total & 831 & 241 & $29.0(25.9-32.1)$ & & 114 & $13.7(11.4-16.1)$ & \\
\hline Family history of DM & & & & 0.052 & & & $<0.001$ \\
\hline Yes & 69 & 13 & $18.8(9.4-28.3)$ & & 20 & $29.0(18.0-40.0)$ & \\
\hline No & 762 & 228 & $29.9(26.7-33.2)$ & & 94 & $12.4(10.0-14.7)$ & \\
\hline Physical activities & & & & 0.283 & & & 0.299 \\
\hline Yes & 278 & 74 & $26.6(21.4-31.8)$ & & 43 & $15.5(11.2-19.7)$ & \\
\hline No & 553 & 167 & $30.2(26.4-34.0)$ & & 71 & $12.8(10.0-15.6)$ & \\
\hline $\begin{array}{l}\text { Frequently of physical } \\
\text { activities }\end{array}$ & & & & 0.426 & & & 0.147 \\
\hline$>4$ times per week & 168 & 47 & $28.0(21.1-34.8)$ & & 30 & 17.9 (12.0-23.7) & \\
\hline 1-4 times per week & 63 & 16 & $25.4(14.3-36.4)$ & & 9 & $14.3(5.4-23.1)$ & \\
\hline $\begin{array}{l}1-3 \text { times per } \\
\text { month }\end{array}$ & 30 & 8 & $26.7(9.9-43.5)$ & & 2 & $6.7(0-16.1)$ & \\
\hline $\begin{array}{l}<1 \text { time per } \\
\text { month }\end{array}$ & 17 & 3 & $17.6(0.0-37.9)$ & & 2 & $11.8(0-28.8)$ & \\
\hline Smoker & & & & 0.036 & & & 0.116 \\
\hline Never smoker & 510 & 134 & $26.3(22.4-30.1)$ & & 61 & $12.0(9.1-14.8)$ & \\
\hline Ex-smoker & 213 & 70 & $32.9(26.5-39.2)$ & & 36 & $16.9(11.8-22.0)$ & \\
\hline Smoker & 108 & 37 & $34.3(25.2-43.4)$ & & 17 & $15.7(8.8-22.7)$ & \\
\hline Drinker & & & & 0.705 & & & 0.454 \\
\hline Drinker & 374 & 106 & $28.3(23.8-32.9)$ & & 55 & 14.7 (11.1-18.3) & \\
\hline Non-drinker & 457 & 135 & $29.5(25.3-33.7)$ & & 59 & $12.9(9.8-16.0)$ & \\
\hline Type of TB & & & & 0.219 & & & 0.070 \\
\hline PTB - smear positive & 391 & 122 & $31.2(26.6-35.8)$ & & 60 & $15.3(11.8-18.9)$ & \\
\hline $\begin{array}{l}\text { PTB - smear } \\
\text { negative }\end{array}$ & 271 & 68 & $25.1(19.9-30.3)$ & & 40 & $14.8(10.5-19.0)$ & \\
\hline EPTB & 169 & 51 & $30.2(23.2-37.2)$ & & 14 & $8.3(4.1-12.5)$ & \\
\hline $\begin{array}{l}\text { TB treatment } \\
\text { category }\end{array}$ & & & & 0.138 & & & 0.815 \\
\hline New & 713 & 200 & $28.1(24.7-31.4)$ & & 97 & $13.6(11.1-16.1)$ & \\
\hline Previously treated & 118 & 41 & $34.7(26.0-43.5)$ & & 17 & $14.4(8.0-20.8)$ & \\
\hline HIV status & & & & 0.722 & & & 0.555 \\
\hline Positive & 16 & 4 & $25.0(1.2-48.8)$ & & 3 & $18.8(10.1-40.2)$ & \\
\hline Negative & 815 & 237 & $29.1(1.6-26.0)$ & & 111 & $13.6(11.3-16.0)$ & \\
\hline
\end{tabular}

TB Tuberculosis; PTB Pulmonary Tuberculosis; EPTB Extra Pulmonary Tuberculosis; DM Diabetes mellitus; $\mathrm{Cl}$ confidence interval; SD Standard deviation; VND Vietnam dong; $B M$ Body mass index

* $p$ value by Kruskal-Wallis test and Cuzick test were used for the nonparametric data and to test for trend across ordered groups 
difference nearly reaching the statistical significance $(p=$ 0.052). (Table 3).

\section{Risk factors associated with DM}

In the crude analysis, the associated factors for DM among TB patients were people aged ' 40 years or older,' 'male' gender, 'family members with a history of DM,' 'pulmonary TB cases' and a 'BMI > 25'. After adjusting for other factors in a logistic regression model, the associated factors for DM among TB patients found in this study were age $\geq 40$ years and a family history of DM. (Table 4).

\section{Additional yield of DM}

Of the 831 screened TB patients, 114 (13.7\%; 95\% CI: 11.4-16.1\%)) were found to have DM, of those, 50 (44\%) were newly diagnosed as DM cases. The number of TB patients needed to be screened to diagnose a new DM case was 17 , and the number of $\mathrm{TB}$ patients needed to carried-out blood testing to diagnose a new DM case was approximately 16 . (Table 5 ).

\section{Discussion}

The prevalence of DM among TB patients in this study was $13.7 \%$ (95\% CI: 11.4-16.1\%), which is much higher than the estimated prevalence of DM among people aged 18-99 in the general population of Vietnam in 2016 (5.34\%; 95\% CI: 4.32-7.32\%) [13]. The prevalence of DM amongst TB patients is also higher than in the previous study in 2006-2008, in Hanoi, Vietnam (8.8\%) [9].

This study showed a $29 \%$ prevalence rate of prediabetes amongst TB cases in Hanoi. The prevalence of prediabetes among TB cases was slightly higher than study findings from India (24.5\%) [14]; and much higher than study findings in Ethiopia (11.5\%) [8]; China (7.8\%) [15]; India $(7 \% ; 8.5 \%)[5,16]$. This finding may indicate an increased relatively higher prevalence of DM among TB patients in the future in Vietnam.

Table 4 Factors associated with DM among TB patients, in Hanoi, Vietnam, $2016(n=831)$

\begin{tabular}{|c|c|c|c|c|}
\hline Characteristics & OR $(95 \% \mathrm{Cl})$ & $p$ value & $\mathrm{aOR}(95 \% \mathrm{Cl})^{*}$ & $p$ value \\
\hline \multicolumn{5}{|l|}{ Age (years) } \\
\hline$<40$ & Reference & & & \\
\hline $40-64$ & $3.56(2.08-6.07)$ & $<0.001$ & $6.09(2.81-13.2)$ & $<0.001$ \\
\hline$\geq 65$ & $3.42(1.88-6.23)$ & $<0.001$ & $2.65(1.65-4.25)$ & $<0.001$ \\
\hline \multicolumn{5}{|l|}{ Sex } \\
\hline Female & Reference & & & \\
\hline Male & $1.74(1.15-2.63)$ & 0.007 & $1.62(0.96-2.75)$ & 0.071 \\
\hline \multicolumn{5}{|l|}{ Family history of DM } \\
\hline No & Reference & & & \\
\hline Yes & $2.35(1.55-3.56)$ & $<0.001$ & $2.71(1.33-5.50)$ & 0.006 \\
\hline \multicolumn{5}{|l|}{ Type of TB } \\
\hline Extra-pulmonary & Reference & & & \\
\hline Smear negative & $1.78(1.00-3.17)$ & 0.044 & $1.26(0.83-1.91)$ & 0.272 \\
\hline Smear positive & $1.85(1.07-3.22)$ & 0.024 & $1.83(0.86-3.93)$ & 0.119 \\
\hline \multicolumn{5}{|l|}{ Smoker } \\
\hline Never smoke & Reference & & & \\
\hline Current smoker & $1.32(0.80-2.16)$ & 0.283 & $0.75(0.33-1.71)$ & 0.494 \\
\hline Ex-smoker & $1.41(0.97-2.07)$ & 0.076 & $0.58(0.31-1.10)$ & 0.094 \\
\hline \multicolumn{5}{|l|}{ BMl } \\
\hline$<18.5$ & Reference & & & \\
\hline $18.5-24.9$ & $1.01(0.70-1.46)$ & 0.945 & $1.03(0.65-1.64)$ & 0.885 \\
\hline$>=25$ & $2.22(1.11-4.42)$ & 0.032 & $2.27(0.75-6.82)$ & 0.146 \\
\hline \multicolumn{5}{|l|}{ Education } \\
\hline Primary or lower & Reference & & & \\
\hline Secondary; high school & $1.09(0.68-1.74)$ & 0.712 & $1.07(0.55-2.05)$ & 0.850 \\
\hline Colleagues/University or higher & $0.86(0.47-1.58)$ & 0.632 & $0.47(0.12-1.84)$ & 0.281 \\
\hline
\end{tabular}

TB Tuberculosis; DM Diabetes mellitus; OR Odds ratio; $a O R$ Adjusted odds ratio; $C l$ Confidence interval; $B M I$ Body mass index

*Adjusted for age; sex; residence; education; occupation; marital status; type of TB; family history of DM and BMI in Multivariate logistic regression 
Table 5 Number of patients needed to screen to find a new DM case among TB patients, in Hanoi, Vietnam, 2016. $(n=831)$

\begin{tabular}{|c|c|c|c|c|c|}
\hline Characteristic & $\begin{array}{l}\text { Total TB patients } \\
\text { evaluated for DM (n) }\end{array}$ & $\begin{array}{l}\text { Number of patients with } \\
\text { previous DM (n) }\end{array}$ & $\begin{array}{l}\text { Number of newly } \\
\text { diagnosed DM patients ( } n \text { ) }\end{array}$ & $\begin{array}{l}\text { Additional } \\
\text { yield (\%) }\end{array}$ & $\begin{array}{l}\text { Number needed to screen to } \\
\text { diagnose a new case ( } \mathrm{n})\end{array}$ \\
\hline Total & 831 & 64 & 50 & 43.9 & 17 \\
\hline \multicolumn{6}{|l|}{ Sex } \\
\hline Male & 549 & 49 & 39 & 44.3 & 14 \\
\hline Female & 282 & 15 & 11 & 42.3 & 26 \\
\hline \multicolumn{6}{|l|}{ Age, years } \\
\hline$<40$ & 289 & 4 & 11 & 73.3 & 26 \\
\hline $40-65$ & 390 & 45 & 27 & 37.5 & 14 \\
\hline$\geq 65$ & 152 & 15 & 12 & 44.4 & 13 \\
\hline \multicolumn{6}{|l|}{ Family history of DM } \\
\hline Yes & 69 & 17 & 3 & 15.0 & 23 \\
\hline No & 762 & 47 & 47 & 50.0 & 16 \\
\hline \multicolumn{6}{|l|}{ Type of TB } \\
\hline PTB - smear positive & 391 & 40 & 20 & 33.3 & 20 \\
\hline PTB - smear negative & 271 & 21 & 19 & 47.5 & 14 \\
\hline EPTB & 169 & 3 & 11 & 78.6 & 15 \\
\hline \multicolumn{6}{|l|}{$\mathrm{BMl}, \mathrm{kg} / \mathrm{m} 2$} \\
\hline Underweight, < 18.5 & 289 & 19 & 19 & 50.0 & 15 \\
\hline Normal, 18.5-24.9 & 518 & 38 & 31 & 44.9 & 17 \\
\hline Overweight, $>=25$ & 24 & 7 & 0 & 0.0 & \\
\hline
\end{tabular}

TB Tuberculosis; PTB Pulmonary Tuberculosis; EPTB Extra Pulmonary Tuberculosis; DM Diabetes mellitus; BMI Body mass index

The prevalence of DM among TB patients in this study $(13.7 \%)$ is slightly lower than the global median DM prevalence among TB patients, estimated at $16 \%$ (IQR 9.0-25.3\%) found by Mahteme et.al [17]. This systematic review had analysed 78 studies reporting DM prevalence among TB patients, representing 33 countries globally. The prevalence of DM amongst TB patients ranged from $1.9 \%$ in Cotonou-Benin to $45 \%$ in the Ebeye-Mashall Islands [18, 19]. Our study results are comparable with the overall median prevalence of DM among TB patients in Asia, estimated to be 17\% (IQR 11.4-25.8\%). The prevalence of DM among TB patients in Asia ranges from $5.1 \%$ in Salury-South India to $44 \%$ in Kerala-India. [5, 17, 20].

The associated risk factors for TBDM comorbidity including sex, age, family history of DM, pulmonary form of $\mathrm{TB}$ and positive sputum smear were found in many other studies [17]. In this study, all the above-mentioned factors were found to be associated factors in the bivariate analysis. However, after multivariate analysis, adjusted for other variables, only increasing age and family history of DM remained significant for factors associated with TBDM comorbidity.

Our study found that age was a significant risk factors for TB and DM comorbidity, a finding consistent with many other studies [8, 14, 17, 20, 21]. In our study, the risk of having DM was 6 times higher in the 40-65 age group when compared to those patients under 40 years old; the risk dropped to approximately 3 times higher in the age group 65 years old and older when compare to age groups of patients less than 40 years old. This may be explained by the link between increasing age and decreases in immune status, one risk factor for both TB and DM [8].

Having a family history of DM is known as a risk factor for DM [7, 12]. Our study also found the risk of DM is 2.7 times higher among TB patients who had a family history of DM. This finding was consistent with other studies conducted in Ethiopia, China, and India $[8,14,17,21]$.

Many studies have also reported a higher prevalence of DM and prevalence of prediabetes amongst males compared to females $[6,20]$. In our study, male TB patients were also identified to have a higher risk of DM in the bivariate analysis. One reasons for this may be a higher frequency of habits such as smoking and drinking alcohol among men. However, the multivariate analysis could not show a significant association.

In this study, $17 \mathrm{~TB}$ cases were needed to be screened in order to diagnose one new DM case. This number is high compared to other studies in Ethiopia (20 cases) [8]; Gujarat-India (25 cases) [16]; and South, India (31 cases) [5]. Such a finding suggests that the implementation of a DM screening strategy for TB patients in Hanoi could be high-value. 
This study also demonstrated that a high level of participation was possible for DM testing amongst TB patients in Hanoi, Vietnam. In 2011, in the collaboration framework, WHO and the UNION have recommended screening for DM among TB patients [3]. Given the high prevalence of DM, especially the high prevalence of prediabetes among TB patients, Vietnam NTP should collaborate with diabetes programme and establish a systematic screening process for DM among TB patients. This program would enable early diagnosis of DM to be made and reduce morbidity and mortality amongst TB patients.

This study has some limitations. As the study was conducted in an urban area, Hanoi city, the findings may not be representative of the entire country, particularly rural areas. Secondly, the study was only implemented among TB patients who were diagnosed and treated in NTP system, thus it may not be representative of TB patients diagnosed and treated in the private or non-NTP public sectors, or TB patients who have not been diagnosed. Thirdly, decisions on the diagnosis of DM were based on FBG only, this testing methodology may be less sensitive than glycosylated haemoglobin or oral glucose tolerance tests. Finally, this study used the standard cut-off points for BMI categories, it did not use cut-off points specific to Asian populations as recommended by the WHO.

\section{Conclusions}

In conclusion, this study illustrated the high prevalence of DM and prediabetes among TB patients in Hanoi, Vietnam. This was especially true for persons aged over 40 years old or who had a family history of DM. Given the high prevalence of DM, particularly the high prevalence of prediabetes among TB patients, this study recommends the Vietnam NTP need to collaborate with diabetes programme to establish a systematic screening process for DM amongst TB patients.

\section{Abbreviations \\ ADA: The American Diabetes Association; BMI: Body Mass Index; Cl: Confidence interval; DM: Diabetes Mellitus; EPTB: Extra Pulmonary Tuberculosis; FBG: Fasting blood glucose; IDF: International Diabetes Federation; IFG: Impaired fasting glucose; IQR: Interquartile range; NTP: National Tuberculosis Programme; OR: Odds Ratio; PTB: Pulmonary Tuberculosis;: SD: Standard Deviation; TB: Tuberculosis; UNION: The International Union Against Tuberculosis and Lung Disease; VND: Vietnam Dong; WHO: World Health Organization}

\footnotetext{
Acknowledgements

We would like to thank the Vietnam NTP, Center for Public Health and Ecosystem Research, Hanoi University of Public Health; Institute of Environmental Health and Sustainable Development study team; and health staff of 30 DTUs in Hanoi and the patients for their kind cooperation and participation in the study.

We thank the Department for International Development (DFID), UK, for funding the Global Operational Research Fellowship Programme in which Nguyen Binh Hoa works as an operational research fellow. La Fondation Veuve Emile Metz-Tesch supported open access publications costs. The funders had no role in study design, data collection and analysis, decision to publish, or preparation of the manuscript.
}

Funding

Not applicable.

\section{Availability of data and materials}

The datasets used and/or analysed during the current study are available from the corresponding author on reasonable request.

\section{Authors' contributions}

HNB, PDP, HVQ, HNT, TPH, APT and NVN contributed to develop the protocol and conducting the study. HNB, PDP and HNT analyzed and interpreted the patient data. NNV, HNB, HNT and PDP were a major contributor in writing the manuscript. All authors read and approved the final manuscript.

\section{Ethics approval and consent to participate}

The study protocol was approved by the Institutional Review Board of the National Lung Hospital, Hanoi, Vietnam. Patients diagnosed with DM received appropriate treatment. Written informed consent was obtained from each participant prior to enrolment.

\section{Consent for publication}

Not applicable.

\section{Competing interests}

The authors declare that they have no competing interests.

\section{Publisher's Note}

Springer Nature remains neutral with regard to jurisdictional claims in published maps and institutional affiliations.

\section{Author details}

${ }^{1}$ Vietnam National Lung Hospital, National Tuberculosis Programme Vietnam, 463 Hoang Hoa Tham street, Badinh District, Hanoi, Vietnam. ${ }^{2}$ Centre for Operational Research, International Union Against Tuberculosis and Lung Disease, Paris, France. ${ }^{3}$ Center for Public Health and Ecosystem Research, Hanoi University of Public Health, Hanoi, Vietnam. ${ }^{4}$ Institute of Environmental Health and Sustainable Development, Hanoi, Vietnam. ${ }^{5}$ Hanoi Lung Hospital, Hanoi, Vietnam. ${ }^{6}$ Vietnam Association for Tuberculosis and Lung Disease, Hanoi, Vietnam.

Received: 18 March 2018 Accepted: 15 November 2018 Published online: 29 November 2018

\section{References}

1. World Health Organization. Global tuberculosis report 2017. World Health Organization Document. WHO/HTM/TB/2017. 2017;23:1-249.

2. International Diabetes Federation.Diabetes atlas. IDF. 8th edition. 2017 Available: http://www.diabetesatlas.org/resources/2017-atlas.html. Accessed 10 Jan 2018.

3. International Union Against Tuberculosis and Lung Disease, World Health Organization. Collaborative framework for care and control of tuberculosis and diabetes. World Health Organization Document. WHO/HTM/TB/2011. 2011;15:1-40.

4. Jeon CY, Murray MB. Diabetes mellitus increases the risk of active tuberculosis: a systematic review of 13 observational studies. PLoS Med. 2008;5(7):e152. https://doi.org/10.1371/journal.pmed.0050152.

5. Achanta S, Tekumalla RR, Jaju J, et al. Screening tuberculosis patients for diabetes in a tribal area in South India. Public Health Action. 2013;3(suppl 1).

6. Shidam UG, Roy G, Sahu SK, Kumar SV, Ananthanarayanan PH. Screening for diabetes among presumptive tuberculosis patients at a tertiary care Centre in Pondicherry, India. Int J Tuberc Lung Dis. 2015;19:1163-8.

7. Viney K, Cavanaugh J, Kienene T, et al. Tuberculosis and diabetes mellitus in the Republic of Kiribati: a case-control study. Tropical Med Int Health. 2015; 20:650-7.

8. Workneh MH, Bjune GA, Yimer SA. Prevalence and associated factors of diabetes mellitus among tuberculosis patients in South-Eastern Amhara region, Ethiopia: a cross sectional study. PLoS One. 2016;11:e0147621.

9. Thanh NP, Khue PM, Sy DN, et al. Diabète chez les nouveaux cas de tuberculose pulmonaire à Hanoï, Viet Nam. Bulletin de la Société de pathologie exotique. 2015;108(5):337-41. 
10. World Health Organization. Definitions and reporting framework for tuberculosis-2013 revision. World Health Organization Document 2013. WHO/HTM/TB. 2013;2:1-40.

11. American Diabetes Association (2016), Diagnosing Diabetes and Learning About Prediabetes, accessed on 10 January 2018, from http://www.diabetes. org/diabetes-basics/diagnosis/.

12. Vietnam government. Decision No. 59/2015/QD-TTg dated November 19, 2015, promulgating multidimensional poverty levels applicable during 2016 2020. Accessed on 08 January 2018, from https://vanbanphapluat.co/decisionno-59-2015-qd-ttg-promulgating-multidimensional-poverty-levels-applicable.

13. International Diabetes Federation.Diabetes atlas. Diabetes by country. Country summary table (18-99 years). In: Available; 2017. http://www. diabetesatlas.org/resources/2017-atlas.html.

14. Viswanathan V, Kumpatla S, Aravindalochanan V, et al. Prevalence of diabetes and pre-diabetes and associated risk factors among tuberculosis patients in India. PLoS One. 2012;7(7):e41367. https://doi.org/10.1371/journal. pone.0041367.

15. Li L, Lin Y, Mi F, et al. Screening of patients with tuberculosis for diabetes mellitus in China. Tropical Med Int Health. 2012;17:1294-301.

16. Dave P, Shah A, Chauhan M, et al. Screening patients with tuberculosis for diabetes mellitus in Gujarat. India Public Health Action. 2013;3(suppl 1):S29-33.

17. Workneh MH, Bjune GA, Yimer SA. Prevalence and associated factors of tuberculosis and diabetes mellitus comorbidity: a systematic review. PLoS One. 2017;12:e0175925.

18. Ade S, Affolabi D, Agodokpessi $G$, et al. Low prevalence of diabetes mellitus in patients with tuberculosis in Cotonou, Benin. Public Health Action. 2015; 5:147-9.

19. Nasa JN, Brostrom R, Ram S, et al. Screening adult tuberculosis patients for diabetes mellitus in Ebeye. Republic of the Marshall Islands Public Health Action. 2014;4(Suppl 1):S50-2.

20. Balakrishnan S, Vijayan S, Nair S, et al. High diabetes prevalence among tuberculosis cases in Kerala, India. PLoS One. 2012;7:e46502.

21. Wang $Q, M a A$, Han $X$, et al. Prevalence of type 2 diabetes among newly detected pulmonary tuberculosis patients in China: a community based cohort study. PLoS One. 2013;8(12):e82660. https://doi.org/10.1371/journal. pone.0082660.

Ready to submit your research? Choose BMC and benefit from:

- fast, convenient online submission

- thorough peer review by experienced researchers in your field

- rapid publication on acceptance

- support for research data, including large and complex data types

- gold Open Access which fosters wider collaboration and increased citations

- maximum visibility for your research: over $100 \mathrm{M}$ website views per year

At $\mathrm{BMC}$, research is always in progress.

Learn more biomedcentral.com/submissions 